\title{
"Uno tiene que tener casa donde nació". Ciudadanía y derecho a la ciudad en Santiago
}

Miguel Pérez. Universidad Alberto Hurtado, Santiago, Chile.

RESUMEN | Durante los años noventa, el Estado de Chile buscó evitar la reaparición de movimientos urbanos, recurriendo para ello a la construcción masiva de vivienda subsidiada. Dicho fenómeno no implicó, sin embargo, mejores condiciones de vida para los pobres. Para convertirse en propietarios, fueron sistemáticamente expulsados de sus barrios de origen y relocalizados en la periferia segregada. Tales dinámicas de expulsión han generado en los últimos años la reemergencia de movilizaciones por la vivienda en Santiago, en las cuales las familias sin vivienda demandan crecientemente el derecho a permanecer en sus barrios de origen. Basado en un estudio etnográfico, este artículo sostiene que dicha demanda expresa una reconfiguración de las luchas urbanas materializada en dos fenómenos: a) la aparición de reclamos por el derecho a la ciudad; y b) la transformación en los modos en que los pobres conciben la ciudadanía y los derechos, sobre la base de un autorreconocimiento como habitantes luchadores, esforzados y sacrificados.

PALABraS ClaVe | vivienda, participación ciudadana, conflicto social.

ABstract | During the 1990s, the Chilean State sought to avoid the reappearance of urban movements by massively building subsidized housing units. The significant building of social housing units did not, however, entail better living conditions for the poor. To become homeowners, they were systematically expelled out of their neighborhoods of origin while being relocated to the segregated periphery. These dynamics of expulsion have brought about the reemergence of housing mobilizations in Santiago, in which poor families in need of housing have increasingly demanded the right to stay in their neighborhoods of origin. Based on an ethnographic study, this article holds that such a demand illuminates a reframing of urban struggles, which is materialized in two phenomena: a) The appearance of right-to-the-city claims; and b) the transformations of the ways in which the poor conceive of citizenship and rights on the basis of a self-recognition as committed, hardworking, and self-sacrificing residents.

KEYwORDs | housing, citizen participation, social conflict. 


\section{Introducción}

La implementación de políticas neoliberales en materia habitacional durante la dictadura de Augusto Pinochet (1973-1990) provocó un cambio radical en la manera en que los pobladores (pobres urbanos) conciben la vivienda social y cómo acceden a ella. Desde mediados de los cincuenta hasta 1973, los pobladores visualizaban la vivienda como resultado de prácticas colectivas de autoconstrucción, lo que en muchos casos dio pie al surgimiento de los llamados "campamentos" (ocupaciones ilegales de terrenos). En contraste, a partir de las reformas urbanas de finales de los setenta, la vivienda comenzó a ser entendida como una mercancía a la cual los pobres podrían tener acceso a través de subsidios estatales y ahorros familiares (Bruey, 2012). Desde entonces, los allegados, ${ }^{1}$ devenidos en actores económicos racionales, se convierten en propietarios de manera individual en el mercado de la vivienda.

Los gobiernos de la transición a la democracia temieron que el fin de la dictadura implicara la reemergencia de protestas masivas por vivienda, expresadas materialmente en una proliferación de tomas de terreno (Hipsher, 1996). Recurriendo a las políticas habitacionales neoliberales del régimen militar, dicha aprensión los llevó a entregar soluciones habitacionales para los más pobres a una escala sin precedentes. Mientras la población chilena alcanzaba los trece millones, durante los noventa el Estado se propuso construir al menos 90.000 viviendas sociales al año (Arriagada \& Moreno, 2006). Esto ayudó a reducir el déficit de vivienda de 918.756 unidades en 1990 a 743.450 en el 2000, disminuyendo el número de hogares sin vivienda de un 53\% a un 37\% (Ministerio de Planificación, 2001). La reducción del déficit habitacional continuó durante las siguientes décadas, cayendo a un total de 459.347 unidades en 2013 (Ministerio de Desarrollo Social, 2014), lo que significa que cerca de un 19,4\% de los hogares chilenos aún no son propietarios de una vivienda.

La creciente inversión en viviendas sociales no ha implicado, sin embargo, mejores condiciones de vida para los pobladores, quienes se han visto forzados a materializar sus anhelos de convertirse en propietarios en la segregada y mal equipada periferia urbana (Ducci, 1997; Tapia, 2011). Para hacer frente a este problema, el primer gobierno de Michelle Bachelet (2006-2010) implementó un subsidio complementario a la localización para financiar proyectos de vivienda en comunas pericentrales y aumentó el subsidio del Fondo Solidario de Vivienda (Castillo, 2013). Sin embargo, dichas medidas parecen no haber sido suficientes. A inicios de esta década, Pablo Trivelli (2011, p. 181) afirmaba que, en el Gran Santiago, "prácticamente no hay ofertas de terrenos por debajo de 1,5 uF" por metro cuadrado, mientras que los proyectos de vivienda social no podrían pagar más de 0,4 uf por metro cuadrado previo a la creación del subsidio de localización. En los últimos años, el alza importante del valor del suelo en gran parte del Gran Santiago ha mantenido, si no profundizado, esta tendencia (Castillo \& Forray, 2014). Esto es lo

1 Término empleado en Chile para referirse a núcleos familiares sin vivienda que residen en casas de otras personas, generalmente la de un familiar. 
que Rodríguez y Sugranyes (2005) acertadamente describieron como el dilema de "los con techo"; a saber, la disyuntiva de quienes, para acceder a la casa propia, han sido forzados a dejar sus barrios para residir en proyectos de vivienda subsidiada en la periferia.

Este contexto explica en gran medida la reemergencia de las protestas urbanas en los últimos quince años; un proceso de removilización que, como examino en este artículo, está estrechamente relacionado a dos fenómenos: a) la aparición de nuevas demandas urbanas por el derecho a la ciudad; y b) la transformación de los términos en los que los allegados conciben la ciudadanía y los derechos a partir de un autorreconocimiento como habitantes urbanos luchadores, esforzados y sacrificados. En este marco, este artículo busca examinar de qué manera las demandas de permanencia territorial por parte de los allegados iluminan formas emergentes de ciudadanía, en donde el acto cotidiano de habitar en la ciudad se convierte en el criterio principal de membresía política. Con ello, daré cuenta de la racionalidad ética y política en que se fundan las nuevas movilizaciones por la vivienda en Santiago y sus alcances en las formaciones de nuevas ciudadanías entre los sectores populares.

\section{El movimiento por la vivienda en Santiago: nuevas demandas territoriales}

A mediados del siglo xx, las transformaciones demográficas de Santiago - de 712.533 habitantes en 1930 a casi dos millones en 1960- conllevaron una crisis de vivienda que tuvo a más de cuatrocientas mil personas (17\% de la población) residiendo en asentamientos informales a fines de los sesenta (Santa María, 1973). En este periodo, los residentes sin casa obtuvieron un importante reconocimiento político a través de las ocupaciones de terrenos, concebidas como una de las principales estrategias para acceder a la vivienda en propiedad. Tal fue la génesis de lo que algunos autores han llamado el "movimiento de pobladores" (Castells, 1973; Garcés, 2002).

Las tomas de terrenos del movimiento de pobladores -altamente organizadas y fuertemente politizadas, producto de la estrecha vinculación entre partidos políticos y moradores sin casa- son, actualmente, casi inexistentes. Algunos plantean que la implementación de políticas de vivienda subsidiada fue exitosa no solo en la construcción de vivienda social, sino también en la pacificación de los pobladores, quienes, transformados en agentes de mercado, habrían internalizado pasivamente el modelo subsidiario de producción de vivienda (Hipsher, 1996; Murphy, 2015; Özler, 2012). La casi total vaporización de las ocupaciones masivas de terrenos y de la autoconstrucción pareciera sostener dicha perspectiva. En este artículo, sin embargo, refuto tales premisas, planteando que las políticas urbanas neoliberales, si bien han producido vivienda masivamente, han generado las condiciones de posibilidad para la reemergencia y reconfiguración de las movilizaciones urbanas por el derecho a la vivienda. Para ello, se analiza etnográficamente este proceso de removilización, examinándose cómo pobladores agrupados en comités de allegados articulan sus reivindicaciones sobre la base de un nuevo lenguaje político anclado en el derecho a la ciudad. Este fenómeno está específicamente materializado en lo que la Federación Nacional de Pobladores (Fenapo) llama "demanda territorial"; a saber, la demanda por obtener soluciones habitacionales en las comunas donde los 
pobladores han nacido y crecido. Este trabajo explora estas protestas planteando que las demandas de los pobladores revelan, al mismo tiempo, una reconfiguración más amplia de sus prácticas de ciudadanía. Propongo, entonces, dos objetivos centrales: a) primero, analizar la "demanda territorial" de los pobladores como un reclamo por el derecho a la ciudad a través del cual el tradicional derecho a la vivienda asumiría nuevas formas; b) discutir en qué medida esta demanda nos permite pensar en el surgimiento de formas de ciudadanía en las que los allegados, al concebirse como residentes esforzados y comprometidos en luchas urbanas, construyen nuevos modos de practicar el ejercicio de los derechos.

Este análisis demuestra, en este sentido, la naturaleza paradójica de las actuales movilizaciones de pobladores en Santiago: a pesar de que tales manifestaciones buscan cuestionar los efectos materiales de las políticas de vivienda subsidiada, al mismo tiempo posibilitan la formulación de ideas y prácticas de ciudadanía permeadas por una racionalidad neoliberal. En esta racionalidad, los allegados se interpretan a sí mismos como individuos morales que "deben construir activamente una vida a través de las elecciones prácticas que realizan sobre sus conductas, y cargar con las responsabilidades individuales de la naturaleza y las consecuencias de sus elecciones" (Rose, 1999, p. 176). Así, este artículo ilustra hasta qué punto los residentes sin casa son capaces de posicionar una agenda de cambio social en un país en el que el mercado se ha convertido en el modo central de gubernamentalidad (Han, 2012).

En metrópolis del llamado Sur Global, los debates actuales sobre ciudadanía y derecho a la ciudad están mayoritariamente basados en trabajos que analizan los efectos transformadores de quienes han participado directamente en los procesos de autoconstrucción (Caldeira, 2017; Holston, 2008; Murphy, 2015). La vasta literatura sobre este problema contrasta, sin embargo, con la poca atención que se les ha prestado a las protestas urbanas enmarcadas en la participación de los pobladores en los programas de vivienda social. Aunque existen algunas importantes excepciones al respecto (Angelcos \& Pérez, 2017; Pérez, 2017), quienes han dado cuenta de este fenómeno en Chile tienden a sostener la imposibilidad de desafiar las políticas de mercado cuando los allegados, en su afán por alcanzar la vivienda en propiedad, hacen uso de estos programas (Hipsher, 1996; Murphy, 2015; Özler, 2012). Para estos autores, la participación en comités de allegados implicaría una internalización de una ética neoliberal en donde los individuos se constituyen como sujetos disciplinados capaces de "conducir su conducta" bajo los principios de responsabilidad, autonomía y autosuficiencia (Ong, 2003; Rose, 1999). Ello, señalan estos trabajos, habría promovido una desmovilización de los pobres, lo que explicaría en gran medida la casi total desaparición del movimiento de pobladores en las últimas décadas. Este trabajo cuestiona dichas concepciones, al demostrar que los pobladores que participan en asambleas de vivienda reguladas por el Estado, a pesar de articular sus demandas ciudadanas a través de una gramática moral neoliberal basada en las ideas de responsabilidad y categorías asociadas -lucha, esfuerzo y sacrificio-, son capaces de resistir el modelo subsidiario de vivienda. De esta forma, aquí sugiero que los discursos basados en el esfuerzo revelan formas incipientes de lo que algunos autores llaman "ciudadanía urbana" (Cohen \& Margalit, 2015; 
Holston, 2008; Holston \& Appadurai, 1996), un concepto que permite examinar cómo ciertos agentes sociales legitiman sus demandas de derechos al reconocerse a sí mismos como hacedores de ciudad comprometidos con el devenir de su comunidad.

Este artículo es el resultado de quince meses de trabajo de campo etnográfico conducidos en Santiago en dos etapas: entre julio de 2013 y agosto de 2014; y entre junio y agosto de 2015. Durante ese tiempo, entrevisté a más de ochenta miembros de distintos comités de allegados de Santiago. ${ }^{2}$ Asimismo, llevé a cabo observación participante en asambleas, reuniones y protestas callejeras realizadas por la Fenapo. El foco del artículo, sin embargo, será el Comité de Allegados Don Bosco de la comuna de La Florida, organización de la cual la mayoría de sus miembros ya son propietarios. Para proteger la identidad de los informantes que aparecen mencionados, todos los nombres propios en este trabajo son seudónimos.

\section{El contexto urbano}

La Florida es una comuna localizada al sureste de Santiago que, según el Censo de 2017, tiene una población de alrededor de 366.916 personas. Durante las últimas cinco décadas, este distrito ha experimentado un cambio importante en la composición de clase de sus habitantes. En los ańos sesenta y a comienzos de los setenta, cuando La Florida era aún parte de la periferia semirrural de Santiago, los pobladores sin casa llevaron a cabo tomas de terrenos y procesos de autoconstrucción bajo la supervisión técnica del Estado. Luego, la implementación de políticas habitacionales neoliberales permitió la construcción de 23.906 viviendas subsidiadas entre 1983 y 1999 (Tapia, 2011). Casi al mismo tiempo, agentes inmobiliarios aprovecharon el bajo precio de los suelos de un municipio que, hasta ese entonces, era considerado periférico, para desarrollar inversiones residenciales y comerciales. Así, en los noventa, los habitantes de La Florida presenciaron la llegada de población de clase media y clase alta que se situó en el área este de la comuna, mayoritariamente en barrios cerrados construidos a los pies de la cordillera de Los Andes (Hidalgo, 2004; Ruiz-Tagle, 2016). Del mismo modo, se inauguraron dos centros comerciales (Plaza Vespucio en 1990 y Florida Center en 2003) y una estación de metro (Bellavista de La Florida en 1997).

Desde entonces, La Florida -al igual que otras comunas de Santiago, como Peñalolén, Huechuraba o Quilicura- ha llamado la atención de planificadores urbanos en tanto expone, en palabras de Sabatini y Salcedo (2007), la colonización de la periferia pobre por parte de los ricos. Participando en los debates contemporáneos sobre mixidad social (social mixing) y segregación residencial (Slater, 2006), algunos autores han analizado en qué medida la coexistencia de familias de bajos y altos recursos en la comuna conlleva nuevas formas de integración social o, por el contrario, procesos de gentrificación y desplazamiento (Hidalgo, 2004; RuizTagle, 2016; Ruiz-Tagle \& López, 2014; Sabatini \& Salcedo, 2007). Como una clara demostración de esta colonización, al comienzo de la década pasada cerca del

2 Movimiento Pueblo Sin Techo (Peñalolén); Techo Ahora (La Pintana); Comité de Allegados Don Bosco (La Florida); y el Movimiento de Pobladores en Lucha (Peñalolén y San Joaquín). 
11\% de los residentes de La Florida eran caracterizados como ABCI-concepto utilizado en la política pública chilena para referirse al $7 \%$ más rico- a partir de datos del Censo de 2002 (Asociación Chilena de Empresas de Investigación de Mercado, 2008). En la década actual, esta tendencia pareciera haberse profundizado, hecho demostrado gráficamente en la figura 1, que muestra la dispersión de los hogares ABCi en Santiago entre los años 2002 y 2013. Ahí, La Florida aparece como un distrito que, junto con el cono de alta renta donde históricamente se han asentado las familias ricas (Providencia, Las Condes y Vitacura), se ha posicionado como espacio residencial para una parte de la elite.

Los cambios socioespaciales recién descritos se han visto acompańados por un incremento sostenido del precio del suelo. Información provista por el economista urbano Pablo Trivelli (El Mercurio, 2012, pp. B8-9) muestra que, entre 1991 y 2011, el promedio del valor del suelo en La Florida creció de 0,68 uf a 9,33 uf por metro cuadrado (23,8 u $\$$ /metro cuadrado y $326,5 \mathrm{u} \$ /$ metro cuadrado, respectivamente). Estos números representan un incremento de casi $1.400 \%$, siete veces más elevado que el incremento observado en el Área Metropolitana de Santiago en el mismo periodo.

Figura I Cambios en la distribución espacial de las familias ABCi en Santiago, 2002 y 2013

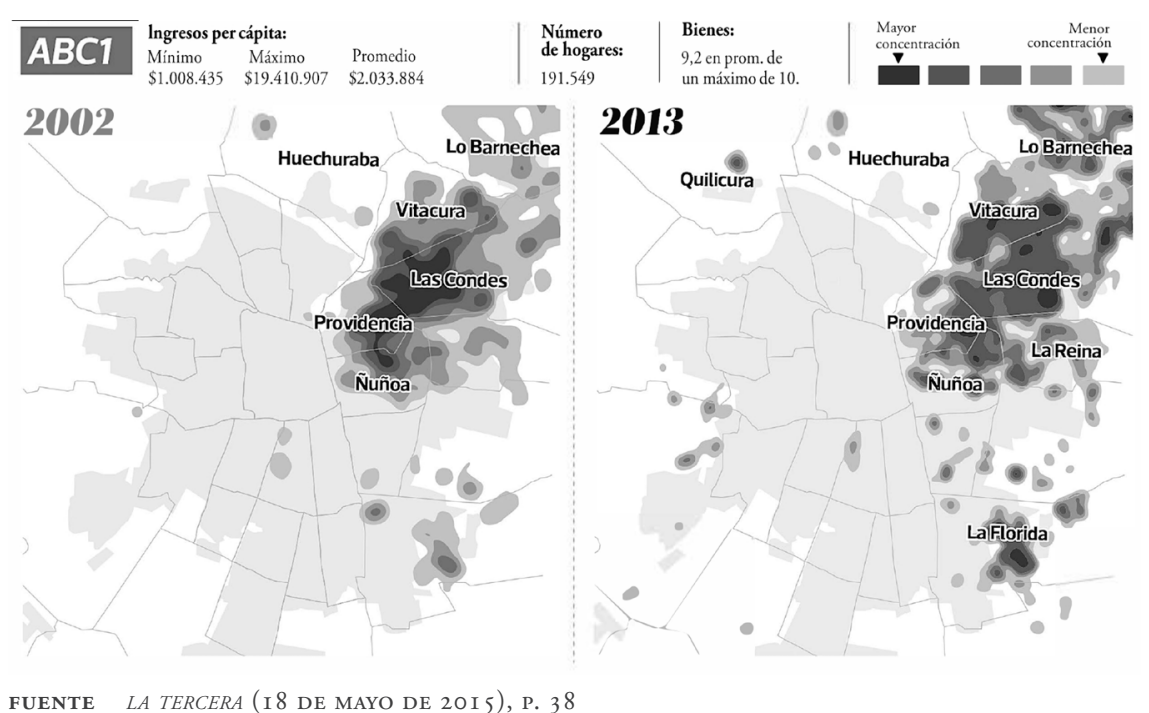

Los proyectos de vivienda social para familias de bajos recursos generalmente son desarrollados en áreas donde los valores no exceden las 0,4 uf el metro cuadrado (Trivelli, 2011). Por lo tanto, el notorio incremento del precio del suelo en La Florida durante los últimos veinticinco años ha generado un problema de acceso a la vivienda para el 16,9\% de los residentes, quienes, según la Encuesta Nacional de Caracterización Socioeconómica (Casen) de 2015, son pobres. Datos oficiales 
entregados por el municipio de La Florida indican que, hasta julio de 2015, 34.983 personas estaban viviendo de allegados, esto es, casi el $9 \%$ de su población. Es precisamente este fenómeno el que ha gatillado la reemergencia de las protestas de los pobladores, por lo que algunos autores, al examinar las estrategias comunitarias destinadas a resistir los procesos de desplazamiento, han llamado al "derecho a quedarse" (the right to stay put; Newman \& Wyly, 2006). Dos conceptos permiten interpretar el fenómeno de movilización por el derecho a quedarse en La Florida: el "derecho a la ciudad" y la "ciudadanía urbana".

\section{Derecho a la ciudad y ciudadanía urbana}

Invitado por los líderes de la Fenapo, en junio de 2014 asistí a una reunión en el Servicio Nacional de la Vivienda (Serviu). En esa ocasión, un alto funcionario de esa agencia estatal, ante la presión de los pobladores por dar respuesta inmediata a sus urgencias habitacionales, señaló:

Nosotros tratamos de darles prioridad a los proyectos de vivienda que permiten a los pobladores permanecer en sus comunas. Nosotros no queremos mandar a los pobres a vivir lejos de sus comunas... pero a veces es difícil, por la falta de recursos.

Durante el trabajo etnográfico que desarrollé, pude observar que, a pesar de esta "falta de recursos", los pobladores visualizaban el derecho de permanencia como un derecho asumido, incuestionable e irrenunciable, que les permitía, al mismo tiempo, luchar contra el desplazamiento al que se ven expuestos producto de la localización preferentemente periférica de los conjuntos de vivienda social. En palabras de Ricardo, un miembro del Comité de Allegados Don Bosco:

Quedarse dentro de la comuna es lo mínimo que uno pude exigir... [Esa exigencia nace] de estar aburrido que la sociedad, a la gente de escasos recursos, los mandé pa' afuera, pa' la periferia. "Ustedes son de bajo nivel, váyanse pa' la periferia...". Como que abusan de la gente por el derecho de tener casa. (Ricardo, 2014)

La constatación de la importancia estratégica que asumía el derecho a quedarse en las comunas de origen en las narrativas políticas de las nuevas generaciones de pobladores, me llevó a plantear dos preguntas que reorientaron mi investigación: (1) ¿podemos pensar en este derecho como un derecho a la ciudad?; (2) ¿puede la formulación de este derecho ser una manifestación de la emergencia de nuevas formas de ciudadanía basadas en la residencia, más que en la pertenencia política a un Estado-nación?

Durante las últimas décadas, cientistas sociales y planificadores han utilizado el derecho a la ciudad como marco analítico para el análisis de protestas que buscan impugnar la persistente desigualdad social en las ciudades (Harvey, 2012; Marcuse, 2009; Mitchell, 2003; Purcell, 2002). Como categoría teórica, el derecho a la ciudad fue, sin embargo, propuesto inicialmente por Henri Lefebvre (1996) en los sesenta como parte de sus reflexiones sobre la ciudad desde una perspectiva marxista. En esta tarea, Lefebvre recurrió a los conceptos de valor de uso y valor de cambio para realizar dos hipótesis: (1) la ciudad ha sido históricamente vinculada al valor de 
uso; la ciudad, afirma Lefebvre, es como una obra de arte creada y apropiada por sus productores; y (2) la generalización de mercancías resultantes de las relaciones de mercado condujeron a la descomposición de la ciudad como obra. La demanda política de Lefebvre conlleva, así, el restablecimiento de la ciudad como una obra de arte capaz de ser producida y apropiada por sus habitantes.

La propuesta de Lefebvre intentaba superar el dogma clásico del marxismo, según el cual el trabajo es la instancia primordial a través de la cual la clase trabajadora adquiere relevancia política. En una sociedad urbanizada, el cambio social resultaría de una experiencia social particular, el habitar, el que es orquestado por una serie de acciones cotidianas clasistamente diferenciadas. Aquí, la segregación de espacios y actividades evidenciaría la incapacidad de los grupos subordinados para ejercer poder hegemónico sobre la producción de espacios urbanos.

A pesar de la orientación revolucionaria del trabajo de Lefebvre, el derecho a la ciudad se ha convertido en un eslogan entre activistas e intelectuales (Purcell, 2002). El derecho a la ciudad es, actualmente, "un significante vacío" (Harvey, 2012, p. $\mathrm{xv}$ ), dependiendo su definición de quienes le suministran un contenido político específico. Esta apertura en el significado es lo que ha permitido a los pobladores de Santiago articular sus demandas actuales por la vivienda como reivindicaciones por el derecho a la ciudad:

Desde la organización y la lucha buscamos obtener una vivienda digna, en cuyo proceso por conseguirla vayamos construyendo un nuevo sujeto [...] capaz de luchar por el derecho a la ciudad y la construcción de un nuevo barrio. (Fenapo, Comunicado Público, abril/mayo 2011)

El derecho a la ciudad de los pobladores habla no solamente de la constitución de movimientos sociales contrarios a la naturaleza excluyente de las políticas urbanas neoliberales, sino también sobre cómo los mismos pobladores han reconfigurado territorialmente sus demandas por el derecho a la vivienda. Resulta crucial, entonces, entender de qué forma la lucha actual por la vivienda ha posibilitado la articulación de nuevos derechos inspirados en los anhelos de los pobladores por continuar residiendo en sus comunas. Esto nos obliga a problematizar un elemento ya relevado por James Holston (2008): la necesidad de analizar las movilizaciones por el derecho a la ciudad en relación con los regímenes de ciudadanía para, de este modo, determinar de qué manera la emergencia de derechos anclados en el acto mismo de habitar permite la formación de modelos alternativos de ciudadanía que asignan derechos a colectivos excluidos.

La ciudadanía ha sido definida como un sistema regulatorio a través del cual las sociedades administran el problema de la pertenencia a la comunidad política (Postero, 2007). El modelo hegemónico de ciudadanía que prima en la actualidad concibe la nación como la comunidad política primordial. Consolidada tras el nacimiento del Estado moderno europeo (Spruyt, 1994), esta formulación nacional de la ciudadanía anuló formas previas de membresía política como, por ejemplo, aquellas basadas en la residencia urbana. Sin embargo, señalan Holston y Appadurai (1996, p. 188), la expansión urbana de fines del siglo ha hecho de la ciudad una "arena estratégica" para reconstruir la noción de ciudadanía y expandirla hacia 
nuevas bases sociales. La urbanización de la sociedad ha contribuido, así, a la emergencia de movilizaciones cuyo propósito es demandar inclusión social a través de la reivindicación por el derecho a la ciudad. Con ello, la pertenencia a una ciudad, materializada en el acto cotidiano de habitar, parece cuestionar las formas de pertenencia nacional en las que se basa la ciudadanía moderna.

Los procesos de autoconstrucción en San Pablo descritos por James Holston (2008) son indicativos de la creciente importancia de la residencia en el régimen de ciudadanía de Brasil. Holston examinó cómo los movimientos por la vivienda en las periferias de dicha ciudad han reconfigurado la noción social de ciudadanía al crear una esfera pública alternativa de participación cívica, que él llama "ciudadanía insurgente”. Esta ciudadanía insurgente presenta tres características: a) considera la ciudad, más que la nación, como la comunidad política primordial; b) la membresía política es definida por la residencia más que por la nacionalidad; c) los derechos distribuidos son entendidos como derechos a la ciudad. Las reivindicaciones levantadas por el comité de allegados estudiado ilustran cómo algunos grupos de pobladores practican formas urbanas de ciudadanía basadas en una comprensión de sí mismos como residentes urbanos comprometidos, esforzados y responsabilizados, dotados de derechos a la ciudad.

\section{"Uno tiene que tener casa donde nació"}

La génesis del Comité de Allegados Don Bosco se remonta al año 2002, cuando cerca de veinte familias de la población Nuevo Amanecer decidieron organizar una demanda muy sentida entre los allegados del sector: obtener soluciones habitacionales en La Florida. El deseo de estos pobladores de continuar residiendo en La Florida tiene una explicación biográfica. La mayoría de ellos son hijos y nietos de los pobladores que, a comienzos de los setenta, participaron en la construcción de su barrio, el antiguo Campamento Nueva La Habana. Una dirigente de la organización señalaba:

A mi hermana le dieron casa en 1984 en Puente Alto [...]. Era una villa con casas de 36 metros cuadrados, de dos pisos, con un patio chico, pero ellos no podrían salir a la calle [porque] que el que era más choro se ganó el espacio de la calle [...]. Por eso nosotros dijimos [nos quedamos] "donde esté la familia cerca" [...] en otros comités no tienen el sentido de comunidad que tiene el Don Bosco. (Adriana, 2014)

El "sentido de comunidad" del que Adriana habla se origina en la historia misma de su barrio. El 1 de noviembre de 1970, más de dos mil familias fundaron el campamento Nueva La Habana bajo la dirección del Movimiento de Izquierda Revolucionaria (MIR). Después de su llegada, los pobladores de Nueva La Habana alcanzaron un acuerdo con el Ministerio de Vivienda del gobierno de Salvador Allende (1970-1973), que les permitió autoconstruir su población. Así, mientras el Estado proveyó de materiales de construcción y asesoría técnica, cientos de pobladores -inscritos en un "frente de trabajadores" que reunía a los residentes desempleados del campamento- participaron de la edificación de sus viviendas. 
El golpe militar de 1973 dejó inconcluso este proyecto. Además de asesinar a varios líderes del campamento, la dictadura cambió su nombre a Nuevo Amanecer y estableció un nuevo sistema de distribución de las viviendas edificadas: aquellas familias que no contaran con la cantidad de ahorros requerida, no podrían residir en las casas que ellos mismos habían construido. Así, mientras algunos comenzaron a habitar las casas nuevas en 1975, muchos otros continuaron residiendo informalmente en lo que se conoce como "campamento viejo". Esta porción de la población está completamente urbanizada y los otrora ocupantes ilegales ya han adquirido títulos de dominio. No obstante, muchos de los hijos y nietos de los propietarios de ambos tipos de vivienda se han visto enfrentados a la falta de soluciones habitacionales en La Florida, cuestión que los ha encaminado a participar activamente en asambleas de vivienda. Buscando convertirse en propietarios en su comuna de origen como forma de preservar lo que Adriana llama el "sentido de comunidad", más de setecientas familias estaban inscritas en el Comité de Allegados Don Bosco en 2015. Su lema de lucha, orgullosamente utilizado en protestas públicas, es decidor: "Porque aquí nacimos y aquí crecimos, aquí nos vamos a quedar" (figura 2).

\section{FIgURA 2 Comité de Allegados Don Bosco protestando frente al Palacio de la Moneda}

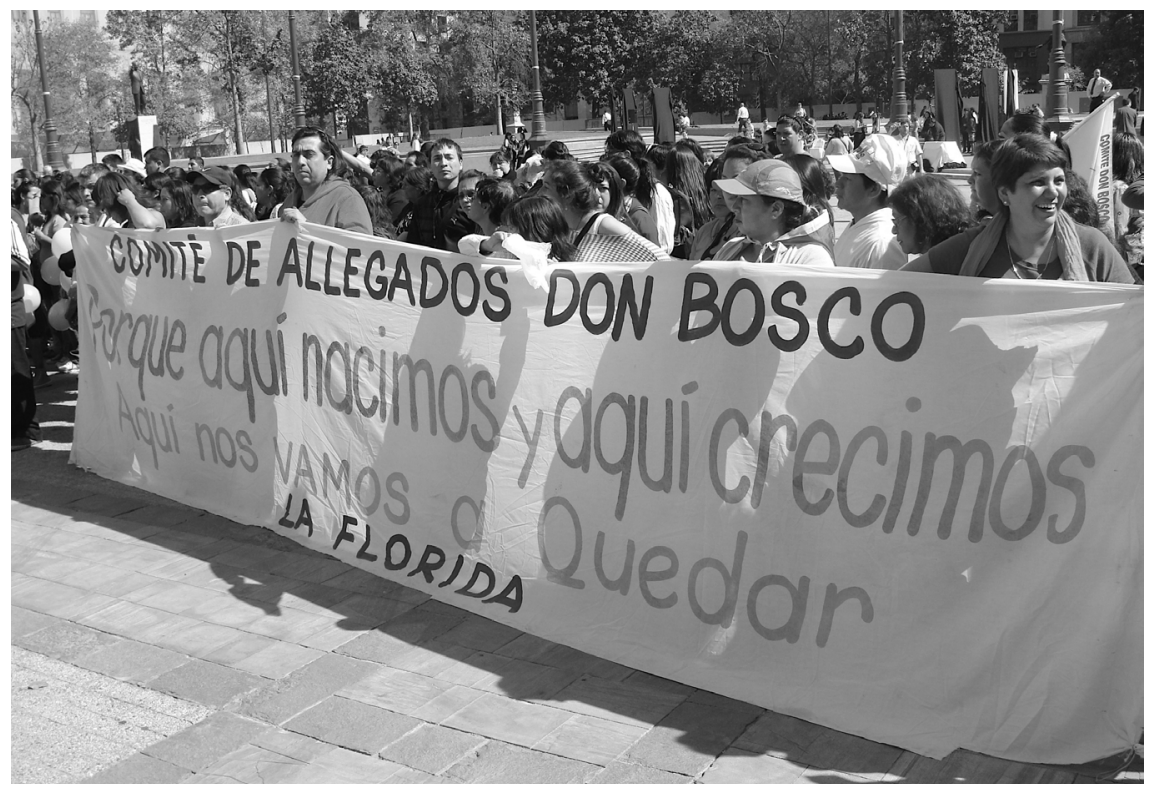

FUENTE ELABORACIÓN PROPIA, 2013

Aquí hay cualquier construcción pa' los ricachones, pero no vivienda social [...]. [Ellos] están invadiendo la comuna porque las constructoras compran terrenos para construir viviendas que valen más de ochenta millones [us\$115.000 aproximadamente]. Entonces, ¿quiénes son los que pierden? Nosotros... ¿por qué no voy a tener el derecho de quedarme acá si he vivido toda mi vida aquí? ¡Los ricos ni siquiera nacieron acá! (Clara, 2014) 
Para Clara, las demandas los pobladores relativas al derecho a permanecer en La Florida tienen un antecedente particular: la "invasión" de los ricos a su comuna de origen. Su formulación territorial de derechos encarna una actualización de las demandas por la vivienda por parte de nuevas generaciones de pobladores. Estas reivindicaciones descansan en gran medida en una recuperación del legado del antiguo movimiento de pobladores, reapropiación que se observa claramente en el discurso de María, una pobladora que nació y se crio en el campamento Nueva La Habana. Ella es una de los ciento sesenta pobladores que, en 2009, conquistaron una vivienda subsidiada a través del Comité de Allegados Don Bosco. En 2014, visité la casa de María para conversar acerca de su anhelo de permanecer en su vecindario. Durante nuestra conversación, ella, notablemente emocionada, dijo:

Mi papá venía a buscar la arena, el ripio, los ladrillos [...] cuando se formó el campamento, todos empezaron a fabricar sus casitas [...] [mi papá] hizo solito su casa $[\ldots]$ uno tiene que tener casa donde nació; por nuestros padres, porque ellos lucharon, po'. Tenemos que quedarnos acá porque Nueva La Habana es nuestra. (María, 2014).

El sentido de pertenencia de María hacia Nueva La Habana / Nuevo Amanecer revela un aspecto conceptualizado por Lefebvre en su derecho a la ciudad; a saber, la idea de que los habitantes urbanos, como productores y creadores de espacio, son capaces de proponer una agenda política por la reapropiación de la ciudad y sus recursos. Para María, al igual que para Clara, la práctica residencial de los pobladores, materializada ya sea en la formación pasada de un campamento o en la reivindicación presente de soluciones habitacionales para los pobres en una comuna "invadida" por los ricos, es la que últimamente legitima la demanda territorial.

Resulta interesante, sin embargo, constatar que dicha formulación de derechos urbanos no se funda en una autoconstrucción material y presente de viviendas. Gran parte de la literatura ha tendido a relacionar la emergencia de nuevos imaginarios de ciudadanía y derechos con la acción concreta de erigir barrios y viviendas desde la informalidad residencial (Caldeira, 2017; Holston, 2008). Sin embargo, las expresiones contemporáneas del movimiento por la vivienda en Chile nos invitan a repensar la manera en que se constituyen estas narrativas políticas que legitiman la demanda de derechos, pues son movilizaciones donde, en su configuración, la ocupación del espacio no asume un rol preponderante.

¿Está la autoconstrucción totalmente ausente? No necesariamente. En mi trabajo de campo era común ver a pobladores remodelando constantemente sus viviendas, aun cuando estas parecían ya estar terminadas. Sin embargo, parafraseando a Levi-Strauss (1974), quiero rescatar la eficacia simbólica de las narraciones casi míticas de la autoconstrucción. En el caso aquí analizado, la autoconstrucción opera simbólicamente como una institución que permite una vinculación entre las biografías personales de cada allegado con las memorias históricas de su barrio. La autoconstrucción, al ser evocada a través de narrativas familiares, funciona como un elemento discursivo fundante mediante el cual los miembros del Don Bosco anclan experiencias individuales a una historia colectiva construida por sus padres y abuelos. Como resultado, se conciben a sí mismos como herederos legítimos de 
derechos territoriales adquiridos por sus ascendientes desde 1970. Es aquí donde surge la movilización por derechos, lo que sugiere que la comprensión subjetiva de los pobladores como hacedores de ciudad puede forjarse incluso en ausencia de la autoconstrucción material de los espacios residenciales.

\section{Prácticas de ciudadanía: una política del esfuerzo}

Si afirmamos que el autorreconocimiento de los allegados como productores de espacio dotados del derecho a quedarse en sus territorios resulta de las memorias colectivas de los procesos de autoconstrucción de décadas pasadas, ¿qué nos dice este entendimiento subjetivo de los pobres urbanos como hacedores de ciudad respecto de sus prácticas y concepciones de ciudadanía? Una respuesta a esta pregunta puede encontrarse al examinar la manera en que los allegados desarrollan sus prácticas políticas en sus asambleas de vivienda, que se conciben como comunidades políticas formadas por miembros con derechos y obligaciones. Dicho análisis permitirá dar cuenta de cómo las acciones cotidianas desplegadas en los comités de allegados revelan el surgimiento de nuevas prácticas de ciudadanía.

Durante el trabajo de campo, noté reiteradamente que los dirigentes del Don Bosco decían "solo los que luchan, ganan". Asimismo, fue común escuchar a postulantes a subsidios aseverar que quienes no luchaban afanosamente en el comité, "no merecen vivienda". La ubicuidad de las categorías "lucha" y "esfuerzo", articuladas la mayoría de las veces en discursos altamente moralizantes, exhibe una característica crucial de la autopercepción de los pobladores como sujetos de derechos; a saber, la idea de que esta condición está estrechamente vinculada al despliegue de un sentido de responsabilidad individual hacia sus familias y su organización. Este aspecto puede ser interpretado como expresión de una ética neoliberal en la cual los ciudadanos, una vez convertidos en sujetos responsabilizados, serían capaces de gobernarse a sí mismos a través de tecnologías de disciplinamiento y control de su conducta (Ong, 2003; Rose, 1999). La capacidad de demandar derechos aparece, de este modo, íntimamente relacionada no solo al acto mismo de lucha, sino también al cálculo racional de acciones a través de las cuales los pobladores buscan activamente conducir sus vidas bajo un riguroso código moral. Para ellos, los derechos no son prerrogativas "disfrutadas pasivamente" -aspecto que, dice Walzer (1989, p. 216), es característico de regímenes de ciudadanía como la moderna-, dado que la movilización efectiva por ellos parece ser la condición para su ejercicio. Sin embargo, este ejercicio se hace posible solo cuando los allegados se constituyen como sujetos morales cuya matriz de conducta descansa en la idea de la responsabilidad individual y autosuficiencia.

Este proceso de constitución de subjetividades queda en evidencia cuando, para establecer juicios éticos y políticos sobre ellos mismos y sobre otros, los allegados articulan discursos basados en el esfuerzo personal y colectivo. Estas ideas de esfuerzo les permiten, por un lado, justificar su condición de sujetos legítimamente dotados de derechos a la ciudad; $y$, por otro, establecer mecanismos prácticos para determinar quiénes son dignos de derechos y quiénes no. Esta práctica particular de ciudadanía descansa en una comprensión doble del esfuerzo: (1) por una parte, 
el esfuerzo se entiende desde una dimensión política que lo conceptualiza como disposición a luchar. Esta definición política de esfuerzo, al vincularse al acto de demandar derechos, permite la producción de definiciones discursivas, estableciendo las condiciones políticas y sociales necesarias para que los individuos ejerzan sus derechos; (2) por otra parte, el esfuerzo es interpretado desde una dimensión ética, expresada en la idea de "sacrificio". Al pensar el esfuerzo en términos éticos, los pobladores manejan conflictos internos en su comité de allegados sobre la base de una definición moral de quiénes merecen derechos.

\section{Esfuerzo como lucha}

Los allegados que participaron en esta investigación concebían los derechos principalmente como una prerrogativa adquirida a través del involucramiento activo en asuntos públicos. Si, por ejemplo, alguien quiere alcanzar la vivienda en propiedad, debe necesariamente "luchar", tanto colectiva como individualmente, por ella. Para los pobladores, este involucramiento es, por ende, una de las tantas manifestaciones de una movilización diaria, permanente y sostenida de los pobres urbanos para subvertir las determinantes materiales de su existencia. El significante lucha es, así, fundamental para capturar la diversidad de prácticas políticas realizadas por ellos, incluyendo tanto las demandas explícitas por derechos en la arena política como demandas más generales por mejores condiciones de vida. La comprensión de la lucha como articuladora de la experiencia popular hace que los allegados, en sus discursos políticos, formulen juicios críticos sobre la desigualdad social en Chile. De ese modo, se generan narrativas sobre los pobres urbanos como una población desposeída cuyos derechos les han sido negados por la sociedad neoliberal.

A comienzos de 2014, María estaba preocupada por el futuro académico de su hijo de diecinueve ańos, quien se había graduado de la enseñanza media en diciembre de 2013 y pretendía empezar estudios universitarios. Estaba inmensamente entusiasmado con la idea de convertirse en estudiante universitario y solía preguntarme sobre programas de estudios que pudiesen ser acordes a sus intereses. Sin embargo, María, quien trabajaba de manera independiente como modista junto a su madre, se sentía frustrada por no tener dinero para pagar la educación de su hijo. Ella significaba esta frustración de este modo:

Para todo tenís que luchar. Para todo. [...] Este país nunca está mirando a los pobres, siempre a los ricos. Por ejemplo, mi hijo, [estando] con unas ganas inmensas de estudiar y no puede, por plata [...] Hasta para la salud hay que pagar: si no tenís plata, te morís nomás. (María, 2014)

Para María, las condiciones de existencia de los pobladores los predispone a luchar para satisfacer sus necesidades. Esta predisposición está basada en un entendimiento de clase sobre el esfuerzo: los pobres, con pocos medios económicos para obtener bienes de consumo libremente en el mercado, deben necesariamente esforzarse más que los ricos para adquirirlos. Como ha sido etnográficamente documentado (Han, 2012), para alimentar a sus familias y tener estándares mínimos de vida, los pobres del Chile neoliberal trabajan horas extra, tienen dos o tres empleos precarios y se endeudan en empresas de retail para obtener préstamos y créditos con intereses 
abusivos. Todo aquello contribuye a la configuración de imaginarios sobre los ricos, quienes son caracterizados como individuos que, dado su poder económico, no estarían predispuestos a participar en luchas políticas para asegurar su existencia. “¿Para qué van a luchar [los ricos] si reciben plata de herencias?", señaló una allegada al explicar por qué, desde su punto de vista, las familias de la elite no "necesitan" luchar por derechos para garantizar su bienestar.

Para los pobladores, el acto mismo de movilizarse por sus derechos es, entonces, la condición necesaria que legitima su despliegue público como agentes políticos capaces de interpelar al Estado mediante un lenguaje de derechos. Esta idea es articulada sugerentemente por Rosa, quien, respecto a la lucha por la vivienda, señaló:

A lo mejor la vivienda es un derecho para todos; claro, todos deberíamos tener un lugar donde vivir... pero igual tenís que ganártela, porque no podís tener todo regalado. (Rosa 2014)

\section{Esfuerzo como sacrificio}

El significante esfuerzo es conceptualizado también como sacrificio, una connotación derivada de la comprensión de las prácticas cotidianas como estructuradas por una sociedad que distribuye oportunidades desigualmente entre sus miembros. En este caso, el concepto de esfuerzo contempla una dimensión ética que resulta en condenas morales a aquellos allegados que, en opinión de sus pares, "no se han sacrificado" lo suficiente para prosperar en la vida. La idea del sacrificio es, entonces, entendida como un aspecto definitorio de la subjetividad de los allegados: ellos, para sobrevivir y sacar adelante a sus familias y a sus comunidades, deben "sacarse la cresta" (trabajar duramente). En ese contexto, aquellos individuos que "no se sacrifican" como otros pobladores están sujetos a una severa crítica moral de sus pares, lo que, en algunos casos, llega incluso a la negación de su condición de sujetos de derechos.

Esta modalidad de concebir los derechos - esto es, como limitados a quienes están moralmente legitimados por la comunidad- se hace evidente en el establecimiento de una serie de normas con las cuales los miembros del Don Bosco buscan administrar los conflictos que, eventualmente, pudieran surgir de la distribución arbitraria o injusta del derecho a la vivienda. Cada comité de allegados enfrenta serias dificultades cuando llega el momento de decidir en qué casa / departamento los futuros propietarios van a, finalmente, residir. Este es un dilema que puede ser expresado en la siguiente pregunta: ¿qué familias tienen el derecho a elegir primero dónde quieren vivir, si todas, como miembros de la organización, tienen los mismos derechos? Para resolver esta paradoja, el Comité de Allegados Don Bosco generó un sistema de evaluación a través del cual la directiva podía medir "objetivamente" el desempeńo de cada postulante en términos del esfuerzo que él o ella hubiera puesto en la lucha por la vivienda.

Este instrumento evaluativo operaba con dos criterios para medir el comportamiento de la gente: el compromiso y la participación. Mientras el primero refería al hecho de estar al día con el pago de la cuota mensual del comité, el segundo aludía al grado de involucramiento de cada individuo en las actividades de la organización 
(marchas, asambleas, reuniones, actividades para recaudar fondos, etcétera). El sistema de medición funcionaba de esta manera: si uno actuaba de manera adecuada -por ejemplo, pagando las cuotas del comité antes de los primeros cinco días de cada mes, según se estipulaba en el reglamento interno-, él o ella recibía un punto, el cual era ingresado en un cuaderno utilizado exclusivamente para este propósito. Por el contrario, si una persona no se comportaba en concordancia con las reglas del comité -por ejemplo, no asistiendo a las asambleas o a movilizaciones públicas-, él o ella no obtendría ningún punto. Por tanto, mientras más responsable era un postulante del comité, más puntos obtendría.

Las implicancias de este instrumento de evaluación resultan más evidentes cuando se lo relaciona con la estructura interna del Don Bosco. Este comité de allegados estaba dividido en grupos de afinidad más pequeños llamados "comunidades", cada una de las cuales reunía desde tres a veinte personas, las que planeaban ser vecinas cuando los proyectos de vivienda estuvieran concluidos. Generalmente, estas comunidades se formaban espontáneamente por postulantes que tenían relaciones familiares o de amistad previas a su ingreso al comité. Para preservar dichos lazos, la organización estableció que la decisión de dónde viviría cada persona -ya sea en qué calle / pasaje o en qué edificio de departamentos- sería establecida de manera colectiva. Esto nos sitúa frente a un punto crítico: a pesar de que el sistema de puntos medía el comportamiento de cada persona, el derecho a elegir dónde vivir no era adquirido por el individuo, sino por la comunidad a la cual pertenecía. Dicho de otro modo, el criterio para determinar quién "ganaba" este derecho no eran los puntos de cada poblador, sino la suma de puntos de quienes constituyen una comunidad. El grupo de afinidad que tuviera más puntos, por ende, podría elegir primero.

Esto traía consigo efectos significativos en la forma en que los allegados interactuaban públicamente, puesto que, al ser miembros de una comunidad, cada uno de ellos debía ajustar su comportamiento para "no bajar los puntos" del grupo del que él o ella formaba parte. En efecto, este mecanismo de distribución de derechos generó numerosas tensiones entre las comunidades "más" y "menos" sacrificadas, conflictos que usualmente asumían la forma de condena pública a los allegados considerados "flojos", "egoístas" u "oportunistas". Estos juicios morales eran comunes en asambleas generales, instancia en la que decenas de pobladores fueron echados de la organización por sus constantes inasistencias o atrasos en los pagos, hechos que eran entendidos como "falta de compromiso con la lucha por la vivienda".

Muchos de los expulsados volvían a las reuniones del comité para justificar sus negligencias y pedir públicamente su reintegración. Durante un periodo de doce meses, fui testigo de dicho rito de exculpación en veinte o más ocasiones, y solo rara vez la asamblea permitió que los expulsados continuaran participando en la organización. Por ejemplo, el 5 de octubre de 2013, una joven mujer notificada de su destitución se presentó para pedir su reincorporación. Ella había estado ausente por más de seis meses, lo cual impactaba negativamente en la puntuación final de su comunidad. Por esta razón, incluso algunos de sus conocidos la querían fuera del comité. Uno de ellos, después de escuchar sus argumentos, le dijo: 
Si no podís venir [a las asambleas], tenís que avisarnos. Todos nosotros tenemos problemas para venir; todos trabajamos, estudiamos y tenemos niños, pero venimos igual.

La disputa verbal escaló y, al darse cuenta de que no sería reincorporada, la joven gritó: “¡me están negando el derecho a la vivienda!”. Para agosto de 2015, más de cuarenta miembros habían sido expulsados del comité, perdiendo, así, el subsidio habitacional que habían obtenido en 2013. Con ello, no podrían seguir participando del comité ni, peor aún, convertirse en propietarios. Esta privación de derechos, si bien trágica para quienes la sufrieron, era, sin embargo, concebida por los pobladores del Don Bosco como una consecuencia lógica de la falta de sacrificio personal de postulantes que simplemente "no merecen derechos".

\section{Reflexiones finales}

Las movilizaciones de pobladores están en una etapa incipiente de rearticulación en que, como en décadas pasadas, los sin casa siguen concibiendo la vivienda como un derecho que debe ser garantizado por el Estado. El análisis etnográfico de dicha protesta demuestra dos hallazgos principales: primero, el referido al contenido y carácter que asume actualmente la demanda por el derecho a la vivienda, la que ha sido reconfigurada por la inclusión de discursos por el derecho a la ciudad y el derecho a permanecer en los barrios. Segundo, la orientación normativa de quienes están involucrados en este proceso de removilización y hacen uso de una ética basada en la responsabilidad, la lucha y el sacrificio cuando significan su condición de ciudadanos urbanos dotados de derechos. El imaginario político de los pobladores, en ese sentido, muestra una racionalidad particular en los movimientos por la vivienda en el Chile actual: a pesar de que se ven permeados por una gramática moral que podría caracterizarse como "neoliberal", se estructuran por reivindicaciones que desafían las lógicas de la acumulación de capital basadas en la especulación del suelo.

Esta paradoja cobra una expresión concreta cuando observamos de qué manera la forma en que los pobladores ejercen e imaginan los derechos da pie al surgimiento de nuevos tipos de ciudadanía. Sostengo que las movilizaciones de allegados han generado una formulación de ciudadanía que se basa en el reconocimiento subjetivo de los pobladores como productores de espacio urbano dotados de derechos a la ciudad. En este sentido, legitiman su demanda por derechos no solo por su membresía formal en una comunidad política nacional, sino también por su participación activa en los asuntos públicos de la ciudad. Es esta dimensión "substantiva" de ciudadanía (Holston \& Appadurai, 1996, p. 190), en oposición a una formal, la que les permite establecer un criterio claro para distribuir derechos: los derechos son solo para "los que luchan".

En un criterio de administración de derechos que descansa en el individuo, ¿cuál es el rol de la comunidad? La primacía del esfuerzo en este modelo deriva de la ejecución de prácticas sociales comunitarias que, en última instancia, dan vida a los comités de allegados. La comunidad es, entonces, el lugar desde donde los pobladores sin casa se movilizan por derechos y desde donde desarrollan actitudes 
éticas hacia ellos mismos y hacia otros. Siguiendo a Nikolas Rose (1999), el rol central de la comunidad en la estructuración de las prácticas políticas y éticas de los pobladores puede ser analizado como revelador del surgimiento de una forma de gubernamentalidad en la que el sujeto se constituye a sí mismo como un individuo moral al transformarse en miembro de una colectividad con la cual tiene obligaciones específicas y vínculos emocionales. De este modo, la comunidad -y las prácticas sociales que contempla y facilita- forma ciudadanos que son responsables no solamente de ellos mismos, sino también de otros. Resulta, sin embargo, interesante notar que esta modalidad de acción social ha hecho posible la reemergencia de protestas urbanas a través de las cuales los pobladores han luchado exitosamente por el derecho a quedarse en sus barrios. De igual manera, la articulación de estas prácticas ético-políticas ha permitido incluso el surgimiento de movimientos políticos de izquierda radical como el Partido Igualdad, organización que en 2013 levantó la candidatura presidencial de la pobladora Roxana Miranda (Angelcos, Jordana \& Sandoval, 2019).

Los aspectos discutidos más arriba demuestran que los programas de vivienda subsidiada operan de dos formas: por un lado, funcionan como un locus estratégico para llevar a cabo tecnologías específicas de una gubernamentalidad neoliberal; por otro lado, son la instancia predilecta de nuevas generaciones de allegados para llevar a cabo movilizaciones urbanas que, siendo diferentes al antiguo movimiento de pobladores en sus tácticas y orientación estratégica, pueden cuestionar el predominio del mercado en la construcción de viviendas sociales. ¿Pueden estas luchas generar la constitución de un movimiento urbano realmente transformador, como el concebido por Lefebvre cuando examina el derecho a la ciudad? Depende de la capacidad de los pobladores de ir más allá de su denuncia del carácter segregador de las políticas subsidiarias. Para ello, es crucial que sus reivindicaciones por derechos territoriales sean vinculadas a una crítica profunda al sistema económico e ideológico de la desigualdad social que estructura la sociedad chilena, lo que requiere un cuestionamiento radical de los fundamentos éticos sobre los que se basa su propia formación como ciudadanos urbanos.

\section{Agradecimientos}

El autor agradece el apoyo del Proyecto Anillos CONICYT pIA soci80033 y del Centro de Estudios de Conflicto y Cohesión Social COnicyt/fondap/ I 5 I 30009.

\section{Referencias bibliográficas}

Angelcos, N., Jordana, C. \& Sandoval, C. (2019). Sólo en el pueblo confiamos: la estructura moral del discurso político radical de los pobladores en el Partido Igualdad. Izquierdas, $46,22-46$. 
Angelcos, N. \& Pérez, M. (2017). De la "desaparición" a la reemergencia: continuidades y rupturas del movimiento de pobladores en Chile. Latin American Research Review, 52(1), 94-109. https://doi.org/10.25222/larr.39

Arriagada, C. \& Moreno, J. C. (2006). Atlas de la evolución del déficit habitacional en Chile, 1992-2002. Gobierno de Chile. https://bit.ly/2P6BY8h

Asociación Chilena de Empresas de Investigación de Mercado (АIM) (2008). Grupos socioeconómicos 2008. Santiago: AIM. https://bit.ly/1Sn1EaD

Bruey, A. J. (2012). Limitless land and the redefinition of rights: popular mobilisation and the limits of neoliberalism in Chile, 1973-1985. Journal of Latin American Studies, 44(03), 523-552. https://doi.org/10.1017/S0022216X12000399

Caldeira, T. (2017). Peripheral urbanization: Autoconstruction, transversal logics, and politics in cities of the global south. Environment and Planning D: Society and Space, 35(1), 3-20. https://doi.org/10.1177/0263775816658479

Castells, M. (1973). Movimiento de pobladores y lucha de clases en Chile. EURE, 3(7), 9-36.

Castillo, M. J. (2013). Producción y gestión habitacional de los pobladores. La autogestión de vivienda en Peñalolén y La Pintana, Santiago de Chile. Boletín $C F+S$, (54), 133-145. https://bit.ly/2CsXeyg

Castillo, M. J. \& Forray, R. (2014). La vivienda, un problema de acceso al suelo. ARQ (Santiago), (86), 48-57. https://doi.org/10.4067/S0717-69962014000100007

Cohen, N. \& Margalit, T. (2015). 'There are really two cities here': fragmented urban citizenship in Tel Aviv. International Journal of Urban and Regional Research, 39(4), 666-686. https://doi.org/10.1111/1468-2427.12260

Ducci, M. E. (1997). Chile: el lado obscuro de una política de vivienda exitosa. EURE, 23(69), 99-115. https://bit.ly/19eUYcj

El Mercurio. (2012, 24 de junio). En tres décadas, el precio del suelo en el Gran Santiago subió casi $1.000 \%$, pp. B8-B9.

Garcés, M. (2002). Tomando su sitio: el movimiento de pobladores de Santiago, 1957-1970. Santiago de Chile: LOM Ediciones.

Han, C. (2012). Life in debt: Times of care and violence in neoliberal Chile. Berkeley, CA: University of California Press.

Harvey, D. (2012). Rebel cities: From the right to the city to the urban revolution. Nueva York: Verso.

Hidalgo, R. (2004). De los pequeños condominios a la ciudad vallada: las urbanizaciones cerradas y la nueva geografía social en Santiago de Chile (1990-2000). EURE, 30(91), 29-52. http://dx.doi.org/10.4067/S0250-71612004009100003

Hipsher, P. L. (1996). Democratization and the decline of urban social movements in Chile and Spain. Comparative Politics, 28(3), 273-297. https://doi.org/10.2307/422208

Holston, J. (2008). Insurgent citizenship: Disjunctions of democracy and modernity in Brazil. Princeton, NJ: Princeton University Press.

Holston, J. \& Appadurai, A. (1996). Cities and citizenship. Public Culture, 8(2), 187-204. https://doi.org/10.1215/08992363-8-2-187

La Tercera. (2015, 18 de mayo). Estudio muestra cómo ha cambiado el mapa social de Santiago, p. 38.

Lefebvre, H. (1996). Writings on cities. Cambridge, MA: Wiley-Blackwell.

Levi-Strauss, C. (1974). Structural Anthropology. Nueva York: Basic Books. 
Marcuse, P. (2009). From critical urban theory to the right to the city. City, 13(2-3), 185-197. https://doi.org/10.1080/13604810902982177

Ministerio de Desarrollo Social, Chile. (2014). CASEN 2013 Vivienda. Sintesis de resultados. Gobierno de Chile. https://bit.ly/1wychbL

Ministerio de Planificación, Chile. (2001). Situación habitacional 2000. Gobierno de Chile. https://bit.ly/2CuFOkV

Mitchell, D. (2003). The right to the city: Social justice and the fight for public space. Nueva York: The Guilford Press.

Murphy, E. (2015). For a proper home: housing rights in the margins of urban Chile, 1960-2010. Pittsburgh, PA: University of Pittsburgh Press.

Newman, K. \& Wyly, E. K. (2006). The right to stay put, revisited: gentrification and resistance to displacement in New York City. Urban Studies, 43(1), 23-57. https://doi. org/10.1080/00420980500388710

Ong, A. (2003). Buddha is hiding: refugees, citizenship, the New America. Berkeley, CA: University of California Press.

Özler, Ş. İ. (2012). The Concertación and homelessness in Chile market-based housing policies and limited popular participation. Latin American Perspectives, 39(4), 53-70. https:// doi.org/10.1177/0094582X10397917

Pérez, M. (2017). "A new poblador is being born": housing struggles in a gentrified area of Santiago. Latin American Perspectives, 44(3), 28-45. https://doi. org/10.1177/0094582X16668318

Postero, N. (2007). Now we are citizens: indigenous politics in postmulticultural Bolivia. Stanford, Ca: Stanford University Press.

Purcell, M. (2002). Excavating Lefebvre: the right to the city and its urban politics of the inhabitant. GeoJournal, 58(2-3), 99-108. https://doi.org/10.1023/ B:GEJO.0000010829.62237.8f

Rodríguez, A. \& Sugranyes, A. (eds.) (2005). Los con techo. Un desafí para la política de vivienda social. Santiago: Ediciones SUR.

Rose, N. (1999). Powers of freedom: reframing political thought. Cambridge, MA: Cambridge University Press.

Ruiz-Tagle, J. (2016). La persistencia de la segregación y la desigualdad en barrios socialmente diversos: un estudio de caso en La Florida, Santiago. EURE, 42(125), 81-108. http:// dx.doi.org/10.4067/S0250-71612016000100004

Ruiz-Tagle, J. \& López, E. (2014). El estudio de la segregación residencial en Santiago de Chile: revisión crítica de algunos problemas metodológicos y conceptuales. EURE, 40(119), 25-48. http://dx.doi.org/10.4067/S0250-71612014000100002

Sabatini, F. \& Salcedo, R. (2007). Gated communities and the poor in Santiago, Chile: functional and symbolic integration in a context of aggressive capitalist colonization of lower-class areas. Housing Policy Debate, 18(3), 577-606. https://doi.org/10.1080/ 10511482.2007.9521612

Santa María, I. (1973). El desarrollo urbano mediante los "asentamientos espontáneos”: el caso de los "campamentos" chilenos. EURE, 3(7), 103-112.

Slater, T. (2006). The eviction of critical perspectives from gentrification research. International Journal of Urban and Regional Research, 30(4), 737-757. https://doi.org/10.1111/ j.1468-2427.2006.00689.x 
Spruyt, H. (1994). The sovereign state and its competitors: an analysis of systems change. Princeton, NJ: Princeton University Press.

Tapia, R. (2011). Vivienda social en Santiago de Chile: análisis de su comportamiento locacional, período 1980- 2002. Revista INVI, 26(73), 105-131. https://doi.org/10.4067/S071883582011000300004

Trivelli, P. (2011). La propuesta de modificación del Plan Regulador Metropolitano de Santiago (PRMS) 100 requiere una justificación más sólida. EURE, 37(111), 179-184. http:// dx.doi.org/10.4067/S0250-71612011000200009

Walzer, M. (1989). Citizenship. En T. Ball, J. Farr \& R. L. Hanson (eds.), Political innovation and conceptual change (pp. 211-219). Nueva York: Cambridge University Press. 